\title{
Residual stresses in AICrN PVD thin films
}

\author{
T.H.T. Pham, E. Le Bourhis, P. Goudeau and P. Guérin.
}

Institut P' CNRS - Université de Poitiers - ENSMA, UPR 3346, 86962 Futuroscope, France

\begin{abstract}
Residual stresses may affect the mechanical stability of high quality coatings such as $\mathrm{Al}_{1-\mathrm{x}} \mathrm{Cr}_{\mathrm{x}} \mathrm{N}$. In this study, two different physical vapour deposition techniques leading to different residuals stress states have been used for depositing $\mathrm{Al}_{1-\mathrm{x}} \mathrm{Cr}_{\mathrm{X}} \mathrm{N}$ coatings varying the chromium content. The structure and residual stress state have been investigated in $\mathrm{Al}_{1-\mathrm{x}} \mathrm{Cr}_{\mathrm{X}} \mathrm{N}$ coatings deposited on silicon substrates using $\mathrm{X}$-ray diffraction, curvature measurements and nanoindentation. The obtained results are compared to literature and commented in view of the coating microstructure.
\end{abstract}

\section{Introduction}

The excellent qualities such as high hardness, good abrasive, sliding wear resistance, high oxidation and corrosion resistance, of AlCrN attracted many researchers. This ternary nitride coating system protects the steel surface very efficiently from chemical attack by casting alloys and retards the formation and propagation of thermal cracks. Mechanical properties like hardness and residual stresses have been surveyed extensively (Fig. 1) with discrepancies appearing between authors [1-7]. Thin films adherent to bulk substrates are often in a state of tensile or compressive residual stress, which may affect their physical properties. In fact, residual stresses influence directly almost all properties of thin films, and thus are of great importance with respect to their usage. Stresses may be divided into three main types: epitaxial stresses, thermal stresses and intrinsic stresses [8]. Latter stresses can result from numerous transformations, such as the film densification during the deposition in the case of sputtered thin films, vacancy or interstitial diffusion, phase's transformations.

\section{Experimental strategy}

Two methods were employed to produce the AlCrN films. Firstly, they were deposited on the silicon (100) by NORDIKOTM3000 Elfa Systems. Two ion sources with neutraliser: Ø100mm R.F. NordikoTM, filament less, multi-target holders (4 positions), targets are $99.99 \%$ metallic $\mathrm{Ar}$ and $\mathrm{Cr}$, the gas was $\mathrm{N}_{2}$. This device has the advantage of high-level ion bombardments being continuously provided during the deposition process. Secondly, films were deposited on silicon (100) by System of vacuum deposits Concept ${ }^{\mathrm{TM}}$ Alliance by Pulverization Magnetron Gencoa ${ }^{\mathrm{TM}} 3$ " (PUMA) with introduction from gas internal and walked on, at $\mathrm{T}=300^{\circ} \mathrm{C}$, targets were $99.99 \%$ metallic $\mathrm{Al}$ and $\mathrm{Cr}$, the gases were $\mathrm{Ar}$ and $\mathrm{N}_{2}$.

This is an Open Access article distributed under the terms of the Creative Commons Attribution-Noncommercial License 3.0, which permits unrestricted use, distribution, and reproduction in any noncommercial medium, provided the original work is properly cited. 


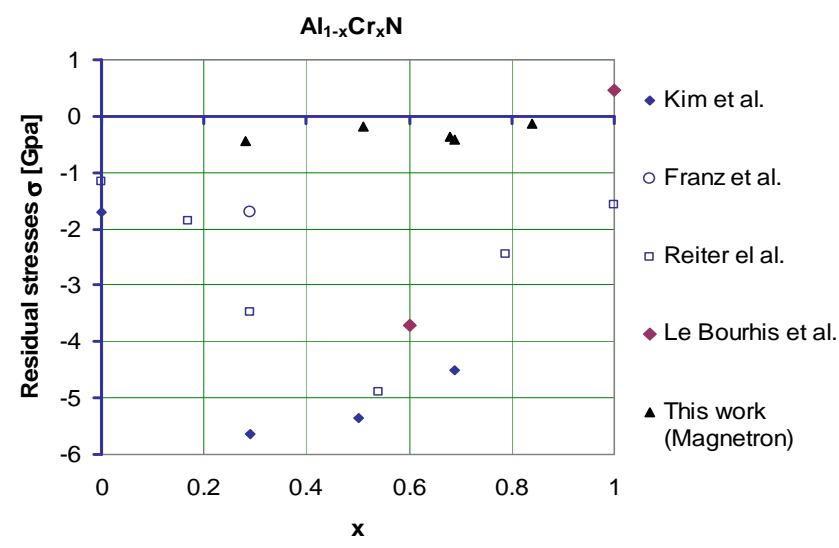

(a)

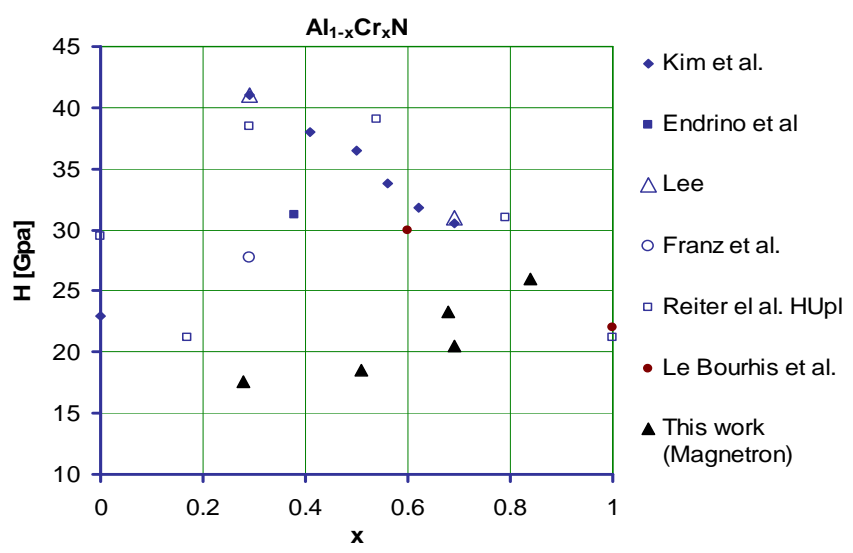

(b)

Fig. 1. Literature survey of (a) residual stresses and (b) hardness published for AlCrN thin films

Energy Dispersive X-ray Spectrometry (EDXS) JEOL- SSM- 5600LV Scanning Electron Microscopy (SEM) was used to determine the chemical compositions of films.

X-ray diffraction (XRD) measurements were conducted in the Bragg- Brentano configuration (reflection mode) on a four-circle Seifert XRD3000 diffractometer working with $\mathrm{CuK} \alpha_{1}$ wavelength $(0.15406 \mathrm{~nm})$, standard slits and a conventional punctual detector. Parameters such as peak position, width and intensity were extracted from all XRD diagrams using the EVA code from Diffract + software package (Socabim) in view of the measured diffraction diagrams available with powder diffraction files (Powder Diffraction File of the International Centre for Diffraction, PDF- ICDD).

Hardness was obtained by nano-indentation experiments at room temperature by a Berkovich diamond pyramid (using a nano-hardness tester machine from CSM -Switzerland). The tests were performed in air with the force control mode of the machine. The loading- unloading procedure was as follows: loading to maximum load in $30 \mathrm{~s}$, plateau at maximum load for $30 \mathrm{~s}$, unloading in $30 \mathrm{~s}$. the maximum load was varied between 0.5 and $300 \mathrm{mN}$. The calibration procedure suggested by 
Oliver and Pharr (1992) was used to correct the data for the load-frame compliance of the apparatus and for the imperfect shape of the indenter tip.

The macroscopic (mean) residual compressive stresses of films were determined by accurate measurement of uncoated and coated substrate profiles with a DEKTAK IIA and using Stoney's formula.

$$
\sigma_{\text {film }}=\frac{E_{\text {substrate }}}{1-v_{\text {substrate }}} \frac{H^{2}}{6 h}\left(\frac{1}{R_{f}}-\frac{1}{R_{i}}\right)
$$

Where $\mathrm{H}$ is the substrate thickness $(\approx 200 \mu \mathrm{m})$, h film thickness, $\mathrm{R}_{\mathrm{f}}$ (final), $\mathrm{R}_{\mathrm{i}}$ (initial) curvatures.

XRD method (so called $\sin ^{2} \Psi$ method) was further used to determine the in-grain stresses $\sigma$. The in-grain residual strain measurements were performed changing the angle $\psi$ between the normal to the surface and the normal to the diffracting planes from 0 to $55^{\circ}$. This can be done for the three following diffracting planes since the film is $<200>$ textured: (111) for $\mathrm{psi}=54.7^{\circ}$, (200) for $\mathrm{psi}=0^{\circ}$ and (220) for $\mathrm{psi}=45^{\circ}$. Stresses were calculated from the strains, using the X-ray elastic constants of the diffracting phase. We employ in the following the logarithm strain usually (and correctly) approximated by the engineering strain in the elastic domain [9]. The well-known $\sin ^{2} \psi$ equation, valid in the case of the existence of an isotropic biaxial stress state has been employed for this purpose [10-11].

$$
\ln (a)=\frac{1+v}{E} \sigma \sin ^{2} \psi-2 \frac{v}{E} \sigma+\ln \left(a_{0}\right)
$$

In the above equations a and $a_{o}$ are the lattice parameter for the stressed and unstressed states respectively, $\mathrm{E}$ and $v$ the elastic modulus and Poisson ratio of the diffracting phase and $\sigma$ the amplitude of the residual stresses. When plotting the $\ln (\mathrm{a})$ as a function $\operatorname{of}^{2} \sin ^{2} \psi$ curves, a linear behaviour is expected and the residual stress is then deduced from the slope of the fitted linear curve while the stress free lattice parameter can be extracted from the ordinate intercept. Deviations from the linearity may be due to texture and elastic anisotropy (oscillations) and/or stress gradient effects $[10]$.

\section{Results and discussion}

The study comprises a wide range of $\mathrm{Al}_{1-\mathrm{x}} \mathrm{Cr}_{\mathrm{x}} \mathrm{N}$ compositions. This paper however focuses on a limited range where the overall experiments detailed above could be carried out. Preliminary results show that the structure is changing with the composition from AlN type hexagonal structure at low chromium content to $\mathrm{CrN}$ type cubic structure at higher $\mathrm{Cr}$ content. A cubic structure with a strong (200) fibber texture is then obtained for $\mathrm{Cr}$ compositions between 60 and 80 at $\%$. For these coatings, Fig. 2 confirms the presence of compressive stresses for both types of deposition techniques except for thicker samples where in-grain residual stresses are tensile with weak amplitude while the global stress measured by curvature method remains the same. This can be due to microstructural changes during film growth.

Taking into account the elastic constants of bulk $\mathrm{CrN}$ ( $\mathrm{E}=256 \mathrm{GPa}$ et $v=0.3$ ), we obtained in-grain residual stress $\sigma$ and stress-free lattice parameter $\mathrm{a}_{0}$ (Table 1). Obtained average stresses are much lower for magnetron specimens and this is to be correlated to the low hardness values that were obtained (Fig. 1). In-grain stress values are twice as large as those obtained using curvature method 
for thin films fabricated by magnetron (Fig. 3a). Those stresses values cannot be compared directly, since XRD yields in-grain information while curvature method averages both crystallites and grain boundaries. However, one may note the $<200>$ texture effects and/or the over-estimate of the elastic modulus. In fact, preliminary results from nanoindentation show that the expected Young's modulus may be much lower (about $40 \%$ ) than the one of pure $\mathrm{CrN}$ given in the literature and increases with Cr content up to 80 at.\%. Furthermore, the system could be elastically anisotropic but the different experimental points on the $\sin ^{2} \psi$ curves are on a straight line so if it exists it must be weak effect. Higher compressive stresses are specific to supported films elaborated by ion-beam sputtering (Fig. 3b) and can be explained by the "atomic peening" phenomenon and the incorporation of impurities, in particular Ar atoms from the sputtering gas.

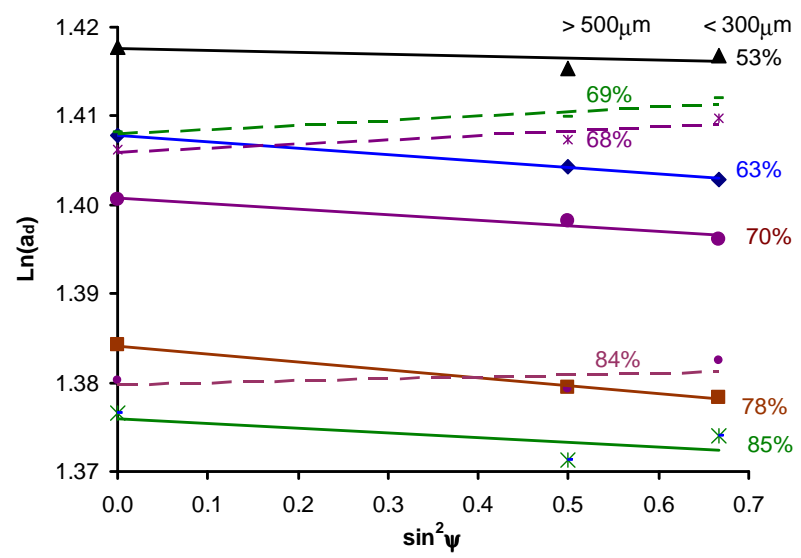

(a)

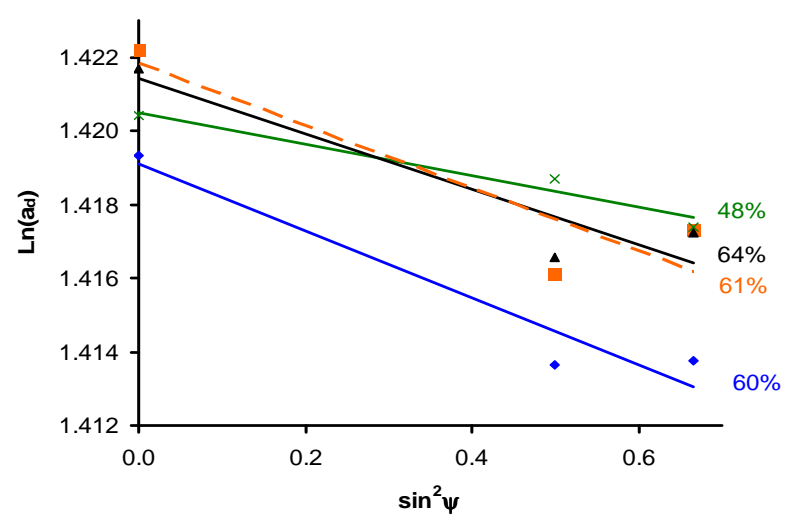

(b)

Fig. 2. $\operatorname{Ln}\left(a_{d}\right)$ as a function of $\sin ^{2} \Psi$ for $\mathrm{AlCrN}$ thin films obtained by (a) magnetron sputtering (PUMA) and (b) ion beam sputtering (NORDIKO).

Chromium is a high melting temperature metal. It is characterized by low atomic mobility at deposition temperature. Aluminum is a metal with relatively low melting temperature and consequently high atomic mobility at the deposition temperature. Due to materials properties, when 
we increase the atomic percent of chromium atoms in the films, the residual stresses tend to decrease in both methods.

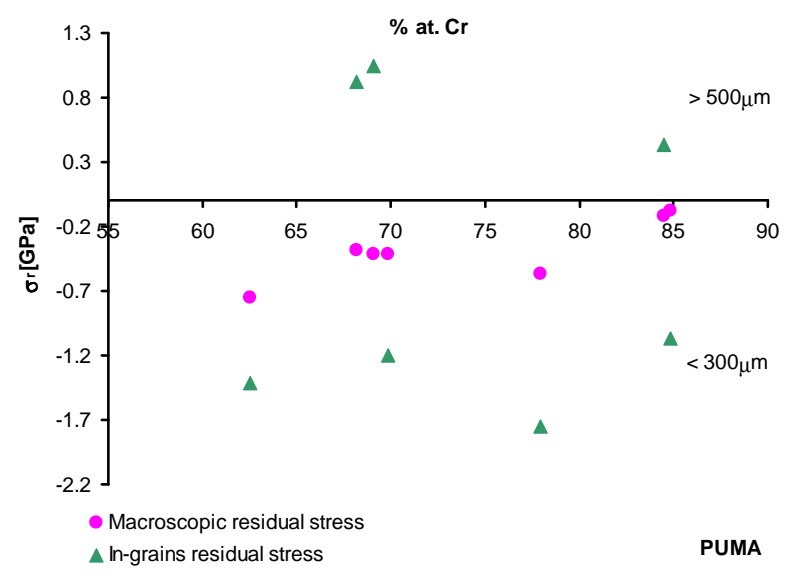

(a)

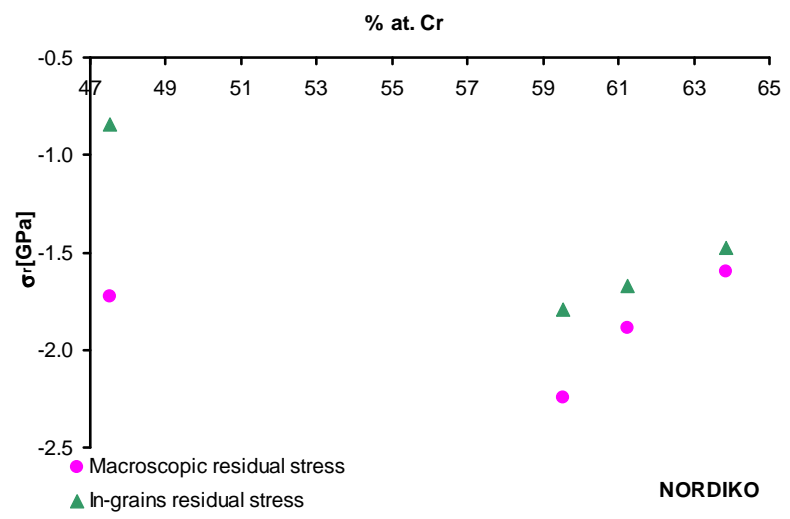

(b)

Fig. 3. Macroscopic and in-grains residual stresses values of $\mathrm{AlCrN}$ thin films elaborated by (a) magnetron (PUMA) and (b) ion-beam (NORDIKO) sputtering

In addition, values of stress-free lattice parameter $\mathrm{a}_{0}$ strongly decreases from 4.13 to $3.97 \mathrm{~A}^{\circ}$ when the atomic percent of $\mathrm{Cr}$ atoms increases from 53 to 85 at. \% for magnetron films while $\mathrm{a}_{0}$ for ion-beam sputtering films tends to slightly increase from 4.14 to $4.16 \mathrm{~A}^{\circ}$ with the increase of $\mathrm{Cr}$ from 48 to 64 at.\% (See Fig. 4). Let us recall that the lattice parameter for bulk $\mathrm{CrN}$ is $4.14 \mathrm{~A}^{\circ}$. For Nordiko samples, the presence of a large amount of interstitial defects associated with Ar atoms incorporation during the energetic ion-beam deposition may explain the lattice parameter increase. However, the strong decrease observed for Puma's samples could be correlated to the variation of nitrogen content in the samples. All these observations illustrate the strong correlation between stresses and microstructure.

Chason et al. (2002) [12] made the important observation that the compressive stress evolution was sensitive to growth rate. In particular, they observed that the steady-state compressive stress was 
lower at higher growth rates. However, Fig. 5 shows that a constant growth rate was employed on most composition range and was identical for both methods.

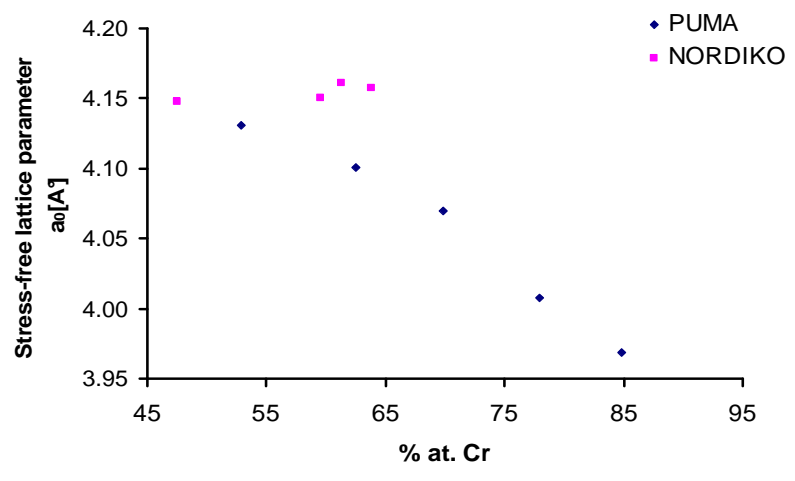

Fig. 4. Stress-free lattice parameter of $\mathrm{AlCrN}$ thin films elaborated by magnetron (PUMA) and ion-beam (NORDIKO) sputtering

Table 1. Chemical composition, stress-free lattice parameter, in-grain residual stress, macroscopic residual stress, of thin films AlCrN elaborated by magnetron (PUMA) and ion-beam (NORDIKO) sputtering

\begin{tabular}{|c|c|c|c|c|c|c|c|}
\hline & $\%$ at. $\mathrm{Cr}$ & Slope & Intercept & $\begin{array}{l}\text { Stress-free lattice } \\
\text { parameter } a_{0}\left[A^{\circ}\right]\end{array}$ & $\begin{array}{l}\text { In-grain residual } \\
\text { stress } \sigma_{\mathrm{r}}[\mathrm{Gpa}]\end{array}$ & $\begin{array}{l}\text { Macroscopic residual } \\
\text { stress } \sigma[\mathrm{Gpa}]\end{array}$ & $\begin{array}{c}\text { Thickness } \\
{[\mu \mathrm{m}]}\end{array}$ \\
\hline \multirow{8}{*}{ 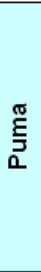 } & 53 & -0.0022 & 1.4175 & 4.131 & -0.43 & -0.62 & $<300$ \\
\hline & 63 & -0.0072 & 1.4078 & 4.101 & -1.42 & -0.75 & $<300$ \\
\hline & 68 & 0.0047 & 1.4059 & 4.070 & 0.93 & -0.38 & $>500$ \\
\hline & 69 & 0.0053 & 1.4079 & 4.077 & 1.04 & -0.41 & $>500$ \\
\hline & 70 & -0.0061 & 1.4007 & 4.069 & -1.20 & -0.41 & $<300$ \\
\hline & 78 & -0.0089 & 1.3841 & 4.008 & -1.75 & -0.57 & $<300$ \\
\hline & 84 & 0.0022 & 1.3798 & 3.970 & 0.43 & -0.12 & $>500$ \\
\hline & 85 & -0.0054 & 1.376 & 3.969 & -1.06 & -0.08 & $<300$ \\
\hline \multirow{4}{*}{$\begin{array}{l}\text { 옿 } \\
\text { 흔 } \\
\text { 는 }\end{array}$} & 48 & -0.0043 & 1.4205 & 4.147 & -0.85 & -1.72 & $<300$ \\
\hline & 60 & -0.0091 & 1.4191 & 4.151 & -1.79 & -2.25 & $<300$ \\
\hline & 61 & -0.0085 & 1.4219 & 4.161 & -1.67 & -1.89 & $<300$ \\
\hline & 64 & -0.0075 & 1.4214 & 4.157 & -1.48 & -1.60 & $<300$ \\
\hline
\end{tabular}

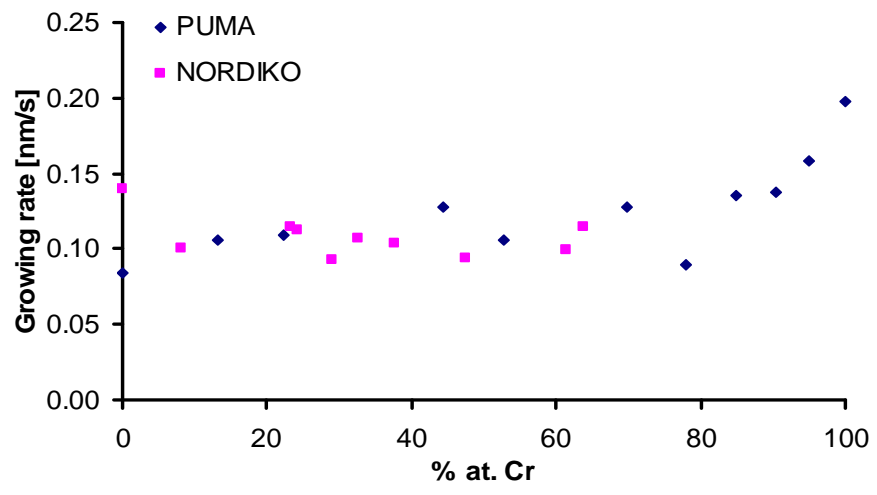

Fig. 5. Growing rate versus \% at. $\mathrm{Cr}$ of $\mathrm{AlCrN}$ thin films elaborated by magnetron (PUMA) and ion-beam (NORDIKO) sputtering 


\section{Conclusion and perspectives}

Cubic AlCrN films have been synthesized by PVD techniques. Global and in grain residual stresses were determined to be weaker for magnetron sputtering as compared to ion-beam sputtering. Residual stresses magnitude decreases with the increase of chromium content in these PVD thin films. The discrepancy between in grain stress and global stress in not yet well understood. It may be attributed to an overestimate of elastic constant used for X-ray stress calculation. Nanoindentation tests show that the Young modulus is much lower than the bulk one and increase with $\mathrm{Cr}$ content. However, these results must be confirmed using Brillouin scattering for example which allows precise analysis of film elasticity.

Further work includes the determination of $\mathrm{N}$ stoechiometry that is known to play important role and may be at the origin of the observed dispersions in the literature. Mechanical properties (Elastic modulus and tribological performance) will be surveyed.

\section{References}

1. E. Le Bourhis, P. Goudeau, M. H. Staia, E. Carrasquero, E.S. Puchi-Cabrera, Surface and Coatings Technology, 203 (2009) 2961.

2. J. L. Endrino, G.S. Rox-Rabinovich, C. Gey, Surf. Coat. Techn. 200 (2006) 6840.

3. R. Franz, J. Neidhardt, B. Sartory, R. Kaindl, R. Tessadri, P. Polcik, V.H. Derflinger, C.Mitterer, Tribology Lett. 23 (2006) 101.

4. G.S. Fox-Rabinovich, B.D. Beake, J.L. Endrino, S.C. Veldhuis, R. Parkinson, L.S. Shuster, M.S. Migranov, Surf. Coat. Techn. 200 (2006) 5738.

5. G.S. Kim, S.Y. Lee, Surf. Coat. Techn. 201 (2006) 4361.

6. S. Lee, Diff. Defect Data Pt. B: Sol. State Phenom. 124-126 (2007) 1609.

7. A.E. Reiter, V.H. Derflinger, B. Hanselmann, T. Bachmann, B. Sartory, Surf. Coat. Techn. 200 (2005) 2114.

8. Doerner, M.F. \& Nix,W.D. Crit. Rev. Solid State Mater. Sci. 14, (1988) 225-268.

9. J. Lu, Handbook of Measurement of Residual Stresses, 343 Fairmont Press, Lilburn, GA, 1996.

10. G. Maeder, Chem. Scr. 26 A (1986) 23;

11. V. Hauk. Structural and residual stress analysis by non destructive methods: evaluation, application, assessment. Amsterdam: Elsevier; 1997.

12. E. Chason, B. W. Sheldon, L. B. Freund, Phys. Rev. Lett. 88 (2002), 156103 